\title{
Effects of Invasion of Water with and without Surfactant on the Oil Production and Flowback through an Oil Wet Matrix-A Microfluidic Chip Based Study
}

\author{
Srikanth Tangirala, James Sheng \\ Bob L. Herd Department of Petroleum Engineering, Texas Tech University, Lubbock, USA \\ Email: james.sheng@ttu.edu
}

How to cite this paper: Tangirala, $S$. and Sheng, J. (2018) Effects of Invasion of Water with and without Surfactant on the Oil Production and Flowback through an Oil Wet Matrix-A Microfluidic Chip Based Study. Open Journal of Yangtze Gas and Oil, 3, 278-292.

https://doi.org/10.4236/ojogas.2018.34024

Received: April 4, 2018

Accepted: October 26, 2018

Published: October 29, 2018

Copyright $\odot 2018$ by authors and Scientific Research Publishing Inc. This work is licensed under the Creative Commons Attribution International License (CC BY 4.0).

http://creativecommons.org/licenses/by/4.0/ (c) (i) Open Access

\begin{abstract}
The invasion of hydraulic fracturing fluids into the matrix through a relatively conductive fracture network causes capillary entrapment of the fluids that lead to the reduction of relative permeability of oil during production. Such a formation damage could be alleviated by the use of surfactants, however, their use does not always guarantee an efficient oil recovery. Through a microfluidic-chip based experimental study, the present work highlights the factors that control the later oil productivity and flowback especially through an oil-wetting matrix. The results from this study indicate that for an oil-wet formation, at shallow invasions, a water-based fracture fluid gives higher later oil production rates than a moderate IFT-reducing surfactant, and at deep invasions, the latter fluid gives better later oil production rates than the former. These results are very useful to the oil industry in making well informed decisions for selecting appropriate fracture fluids to stimulate oil-wet formations.
\end{abstract}

\section{Keywords}

Invasion, Flowback, Surfactant, Microfluidics, Fracture

\section{Introduction}

Hydraulic fracturing technique is used in horizontal wells to improve the drainage area of the oil production by creating high conductive passage way for oil to flow from far-off regions into the wellbore. Almost $51 \%$ of the US daily production is accounted to hydraulic fractured wells [1], and these production trends, in general, are predominantly dominated by fracture flow but the 
late-time production is supported by the matrix surrounding the fractures [2]. During the hydraulic fracturing process, the fluids are injected at a high pressure into the subsurface owing to which they get invaded into the matrix through the fractures. In some cases, soaking operation is even performed to allow for the imbibition of fracture fluid into the matrix from the fractures. Primarily, these processes lead to formation damage, in terms of reduction in the relative permeability of oil, if the flowback of the invaded fluid accompanying the production of oil is inefficient.

The amount of flowback of the invaded fluid is influenced by the capillary entrapment of the fracture fluids within the matrix. In water-wet rocks, it is observed that the water block formed by the invaded fracture fluid predominantly exists at the matrix-fracture interface due to the capillary discontinuity between the high-permeable fracture and low-permeable matrix space surrounding it [3] [4]. In a recent experimental study done by Liang et al. (2015) [5] over a water-wet limestone outcrop, for a very low rate of production, it was observed that a shut-in operation following the invasion of the fracture fluid redistributes the water block formed at the matrix-fracture interface into the interior of the formation due to spontaneous capillary imbibition. Even without any preceding shut-in operation, an instantaneous and prolonged production phase following the invasion of fracture fluid resulted in the removal of water-block away from the fracture face and into the formation [6]. Similar explanation for the case of an unconventional fractional wetting rock was given by Bertoncello et al. (2014) [7] where they showed that the excess water saturation accumulated in the oil-wet pores near the fracture face was reduced after a shut-in operation when the water was imbibed into the water-wet pores in the interior of the formation. Sometimes repeated shut-in operations need to be performed to remove the accumulated water saturation as they attain levels higher than the immovable water saturations [5]. The effect of capillary redistribution of the water block, either in the presence of an external viscous force or in the absence of such forces, has been mostly reported for the water-wet tight formations where the capillary forces of imbibition are very high. On the contrary, the capillary imbibition of water saturation deeper into the formation could cause additional formation damage due to the extended interaction time of the invaded fluid with the formation, especially when clayey formations are involved [8]. In oil-wet rocks, the water block is observed to be caused by the capillary trapping of invaded fracture fluid in the interior of the porous space, rather than at the matrix-fracture interface [9]. In such a case, shut-in procedures during the production phase are not expected to show any improvement in the oil relative permeability, compared to the case of water wetting formation, due to the lack of capillary imbibition phenomenon.

Another solution, which is proposed to reduce the water blocks and to remove their induced formation damage, is the application of surfactant-based fracture fluids. In water-wet rocks, it is shown that a Winsor type-I surfactant solution has reduced the water block and improved the oil relative permeability higher 
than the other Winsor-type surfactants [6]. Kim et al. (2016) [10] have demonstrated through experiments that for reservoir conditions exhibiting low pore-throat to pore-diameter ratio or having cases with constraints on production flow rates, a significant reduction in IFT (around one order of magnitude from $27 \mathrm{mN} / \mathrm{m}$ ) by the treatment with a surfactant would mitigate the formation of water blocks either entirely or moderately. Hence, the use of a surfactant is a possible alternative to improve oil productivity in oil-wet formations, by increasing the capillary number and thus reducing the capillary force of entrapment of the invaded fracture fluids.

In conventional water flooding cases, the capillary numbers range from $10^{-7}$ to $10^{-5}$, which indicates the high impact of capillary pressure over the fluid flow dynamics at pore-scale [11]. Apart from that, the macro scale flow dynamics are also influenced by the capillary gradients across the fluids distributed within the formation. Longoria et al. (2015) [12] have observed that in a water-wet low permeability formation, as the difference in the average water saturation is high between the fracture fluid invaded region and the initial water saturation in the interior of the formation, the late-time oil productivity is also high. This phenomenon arises due to the high degree of capillary gradient observed across the invaded and the uninvaded region which aids in the removal of water block observed at the matrix-fracture interface in such water-wet formations. In an oil-wet formation, the macro-scale effect of capillary pressure gradients is not yet explored, and hence in this present experimental study, the amount of the invasion of fracture fluid into the matrix is taken as a variable parameter which is observed to influence the capillary gradient across the chosen oil-wet porous medium and the fracture space. The effect of the surfactant is also considered as another parameter in the current study which influences the aforementioned capillary pressure gradient. The impact of these parameters on the flowback and later oil productivity is the primary concern of this study's experimental investigation. Such a measurement of final oil rate qualitatively represents the reduction of invasion-created formation damage within the matrix space adjacent to the fracture formed during the hydraulic fracturing operation.

For the sake of the ease of experimental investigation and having the flexibility of visualizing both pore scale and macro scale phenomena occurring inside the porous media, microfluidics-based tools are applied in this study. In this field of application, a state-of-the-art microchip model is fabricated with a custom designed porous network etched on its surface that is used to inject the desired solutions at certain operating conditions like invasion amounts, flowback rates and injection pressures. The application of such a tool is also referred to as a Reservoir-on-a-Chip based approach in the petroleum industry, whose utilization has broadened the scope of understanding the oil recovery mechanisms through pore scale fluid flow behavior and interactions of typical water-based fracture fluids [13]-[18] and surfactant, polymer-based fracture fluids in the reservoir [11] [19]-[27].

Currently, significant research is not available in the application of microflui- 
dics studying the invasion of fracturing fluid and its flowback characteristics. In addition to water, the application of a moderate IFT-reducing surfactant as a fracturing fluid is studied through microfluidics. The effect of invasion volume on the amount of flowback and the extent of formation damage occurring during the process is analyzed for both fracturing fluids. Two commercially available surfactants of non-ionic and anionic nature are utilized in the experimentation as invading fracture fluids, so as to categorically represent the moderate IFT-reducing group of surfactants. The experiments are conducted in an oil-wetting microfluidic glass chip, where the non-wetting fracture fluids are injected from the inlet side of the chip to represent the invasion phase and subsequently, the oil is injected from the exit side of the chip to represent the flowback of the invaded fluids. The fluid saturations inside the chip, at different stages, are observed under a microscope, following which the images of the whole chip are acquired and processed to compute the saturations of the two phases inside the chip. It is observed that as the invasion efficiency increases, the flowback efficiency decreases more for the water-based fracture fluid as compared to that for a moderate IFT-reducing surfactant based fracture fluid. Moreover, the later oil production rates also indicate that for deep invasions, the surfactant as invaded fluid shows higher oil productivity than water-based fluid. But at shallow invasions, it is observed that a water-based fracture fluid gives a higher oil productivity at later times than a surfactant-based fracture fluid.

\section{Methodology}

\subsection{Experimental Materials}

A $45 \mathrm{~mm} \times 15 \mathrm{~mm}$ borosilicate glass chip that is etched by the process of Chemical vapor deposition forming a uniform channel porous media network ( $20 \mathrm{~mm} \times$ $10 \mathrm{~mm}$ footprint) is used for studying the flow of fluids. The chip is manufactured by Micronit Microtechnologies B.V., Netherlands. The channel width and height dimensions are $50 \mu \mathrm{m}$ and $20 \mu \mathrm{m}$ respectively. The porosity of the porous network is 0.6 with single inlet and outlet nodes. A fluorinated type coating over the channels is rendered during the fabrication process of the chip to make the channels hydrophobic (oil-wet). At the entry to the uniform pore network, a single wide pore channel distributes the injected fluids evenly across the whole cross sectional area of the pore network. This portion of the chip represents the fracture region where the fluid is collected first before entering into the matrix region represented by the porous media channels (Figure 1).

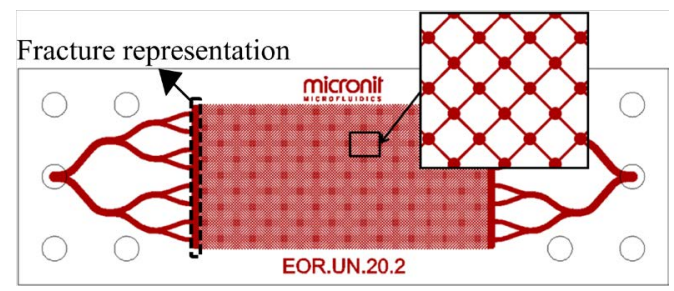

Figure 1. Oil wet EOR microchip with uniform porous network. 
The chip is housed in a Fluidic connect PRO chip Holder purchased from Micronit, which is fixed over the mechanical stage of a fluorescence-imaging inverted microscope (Olympus CKX-53). The fluids are pumped using an air compressor whose pressure is controlled by a pressure based flow controller, MFCS-EZ, purchased from Fluigent Inc. The flow rates in the flow lines are measured using the Flow Rate Platform (FRP) also acquired from Fluigent Inc., having a measurable range of $0-7 \mu \mathrm{l} / \mathrm{min}\left(1 \mu \mathrm{l}=10^{-9} \mathrm{~m}^{3}\right)$. Before allowing the fluids to pass through the chip, they are filtered using a $2 \mu \mathrm{m}$ in-line PEEK filters provided by IDEX corporation.

The oil used in the experiments is soltrol-130 supplied by Chevron Phillips Chemical Company having a dynamic viscosity of $2.37 \mathrm{cp}$ and a specific gravity of 0.74. Deionized water (DI water) is used for conducting immiscible displacements of oil, where the IFT between soltrol oil and DI water, measured using a Du-Nuoy Ring tensiometer is $32.92 \pm 0.27 \mathrm{mN} / \mathrm{m}$. A non-ionic surfactant chemical, supplied by ChemEOR Inc., is diluted to $0.05 \mathrm{wt} \%$ using DI water and is used to displace soltrol oil in the chip, giving an IFT with oil of $1.64 \pm 0.15$ $\mathrm{mN} / \mathrm{m}$ as measured from the M6500 Spinning drop tensiometer purchased from Grace Instrument Company. Another moderate IFT-reducing chemical, an anionic surfactant supplied by Stepan Company, diluted to $0.2 \mathrm{wt} \%$ so as to give an IFT with soltrol oil of $1.94 \pm 0.07 \mathrm{mN} / \mathrm{m}$, is also used to corroborate the results obtained with the non-ionic surfactant. Fluorescein dye, purchased from Sigma-Aldrich, which is soluble only in the aqueous phase, is used to distinguish the multiple fluids, when their saturations are viewed under the microscope.

\subsection{Experimental Setup \& Procedure}

The schematic of the microfluidic experimental set-up is represented in Figure 2.

The invasion and flowback processes are conducted at a constant injection pressure condition of 80 mbar. Such an operating condition of constant injection pressure rather than constant rate represents the analogous field case scenario having a constant average reservoir pressure during the initial stages of production. The fluorescein-dyed aqueous solution injection process into the soltrol oil saturated chip is shown along the solid blue arrows in Figure 2. After the required

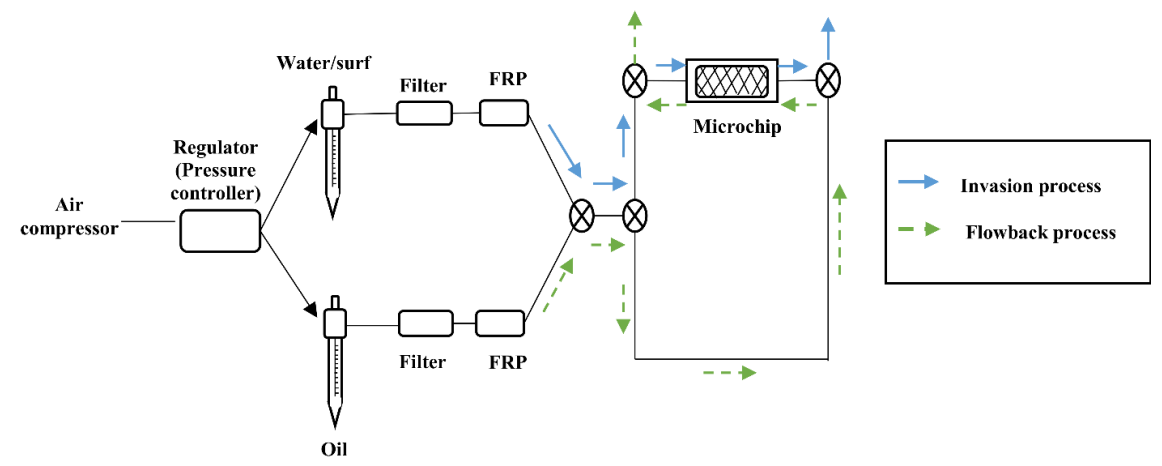

Figure 2. Schematic of experimental set-up. 
amount of pore volume is injected, the valves at the outlet and the inlet are closed, and the manual image acquisition of the whole chip is done. A $2 \mathrm{x}$ objective lens is utilized in the process to acquire the individual images of adjacent portions of the chip, which are stitched together using the Olympus STREAM software to get the whole image of the chip. Subsequent to the image acquisition process for the invasion, the soltrol oil is injected from the exit end of the chip to create flowback phenomenon, as shown by the dashed green arrows in Figure 2. Upon the visual inspection, the change of saturations observed after approximately $10 \mathrm{PV}$ (pore volumes) of oil injection are negligible, at which time the measured stabilized flow rate of oil injected is noted from the FRP which is the same as the flow rate of oil production $\left(Q_{\mathrm{o}}\right)$. This final flow rate measurement is representative of the amount of reduction of formation damage occurred during the invasion process. After the measurement, valves are closed once again at the inlet and the exit end of the chips for the image acquisition process. For image processing, the stitched image is cropped to cover only the boundary of the entire porous media footprint and is converted to a binary image format from RGB format using ImageJ software. The saturations of the fluids are hence computed by analyzing the histogram of the black and white colors from the obtained binary image. The same chip is used for all the experiments and prior to each experiment, a cleaning fluid sequence comprising a repeated flush of DI water and followed by isopropanol and air drying, is applied to clear the flow passage of any residual fluids.

The wettability of the oil wet chip is retained even upon using different fluids for invasion process. Contact angle measurements of the residual blobs of the invaded fluids along their interface with the soltrol oil are measured and represented in Figure 3. They depict an angle of slightly over $120^{\circ}$ and do not show much variance with all three invasions fluids i.e. water, non-ionic and anionic surfactants, indicating the retention of oil-wetting nature of the chip.

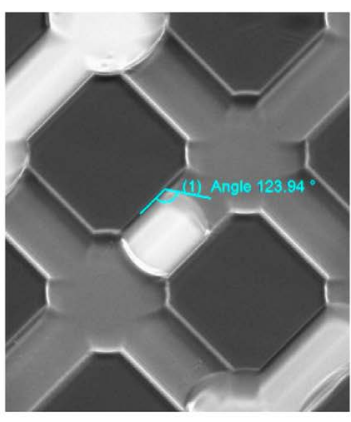

(a)

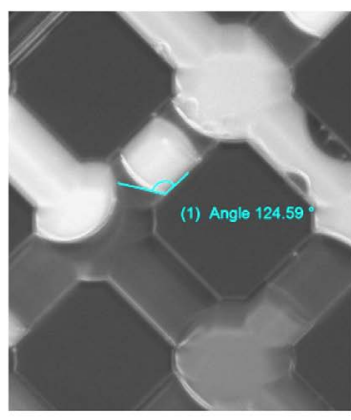

(b)

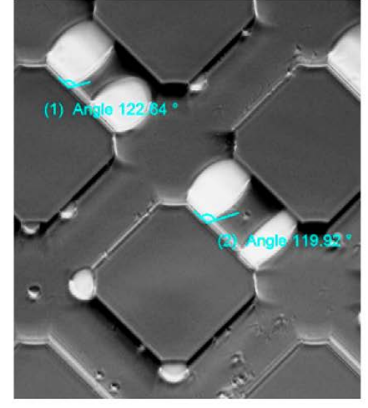

(c)

Figure 3. Contact angles showing oil wettability when measured between soltrol oil medium (grey color) and (a) water $\left(123.94^{\circ}\right)$; (b) non-ionic surfactant $\left(124.59^{\circ}\right)$ and (c) anionic surfactant $\left(122.84^{\circ}, 119.92^{\circ}\right)$, which are represented as white shaded residual blobs.

\section{Results and Discussion}

The results of the microfluidic flow experiments are summarized in Table 1 and 
Table 1. Summary of microfluidic experimental results.

\begin{tabular}{cccccc}
\hline \multirow{2}{*}{ Invasion fluid } & \multicolumn{5}{c}{ Experimental data } \\
\cline { 2 - 6 } & Invasion/\% & $S_{\mathrm{w} 2} / 1$ & Flowback $/ \%$ & $Q_{\mathrm{o}} /\left(\mu \mathrm{l} \cdot \mathrm{min}^{-1}\right)$ & $N_{\mathrm{ca}}\left(\times 10^{-5}\right)$ \\
\hline \multirow{3}{*}{ Water } & 12.14 & 0.004 & 96.97 & 2.949 & 2.855 \\
& 20.45 & 0.007 & 97.71 & 4.366 & 4.226 \\
& 39.65 & 0.141 & 64.40 & 1.801 & 1.743 \\
& 45.11 & 0.353 & 21.66 & 0.000 & 0.000 \\
\hline \multirow{3}{*}{ Non-ionic } & 11.61 & 0.023 & 80.00 & 2.468 & 48.97 \\
& 17.21 & 0.040 & 76.84 & 2.800 & 55.56 \\
& 42.46 & 0.158 & 62.72 & 2.186 & 43.37 \\
Anionic & 48.61 & 0.196 & 59.68 & 1.260 & 25.00 \\
surfcatant & 13.44 & 0.008 & 94.04 & 3.493 & 57.52 \\
& 23.20 & 0.016 & 92.97 & 3.702 & 60.96 \\
& 31.47 & 0.053 & 83.15 & 3.126 & 51.47 \\
& 48.77 & 0.080 & 83.70 & 2.910 & 47.92 \\
\hline
\end{tabular}

the processed microchip images after both invasion and flowback profiles of water and the two surfactants are depicted in Figures 4-6. The low injection pressure of 80 mbar during the production phase, ensures the capillary numbers $\left(N_{\mathrm{ca}}=\mu_{\mathrm{o}} Q_{\mathrm{o}} / \phi A \sigma\right)$ which are low and of the order $10^{-5}$, which are typical for the cases in conventional formations where the capillary forces are dominant [11]. The saturation of aqueous fluid after the invasion is given by $S_{\mathrm{w} 1}$ with its percentage value denoted as Invasion efficiency (\%) and the residual saturation of invaded fluid during production phase is given by $S_{\mathrm{w} 2}$.

Invasion
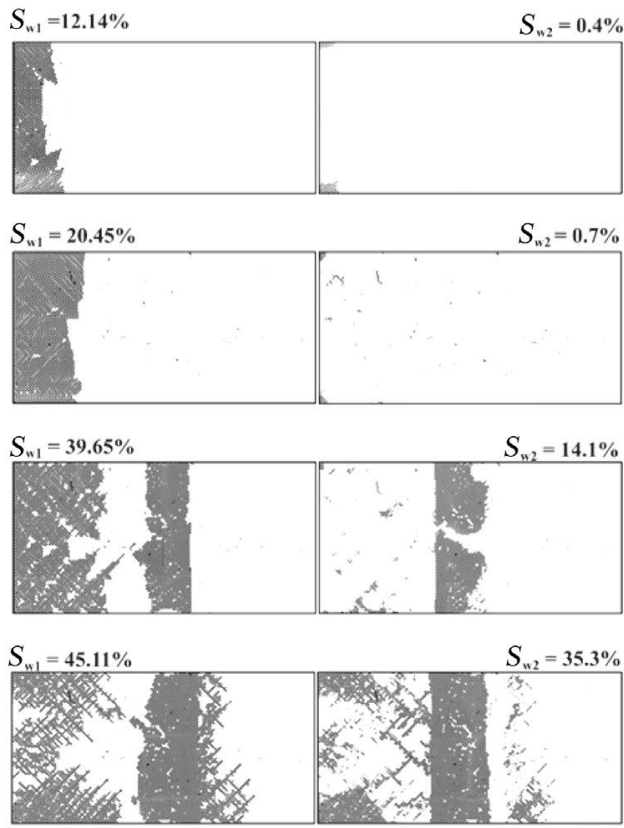

Figure 4. Water as invaded fluid (represented by black color), showcasing the stitched microchip images after invasion (left column) and after flowback (right column) for different invasion efficiencies. 
Invasion
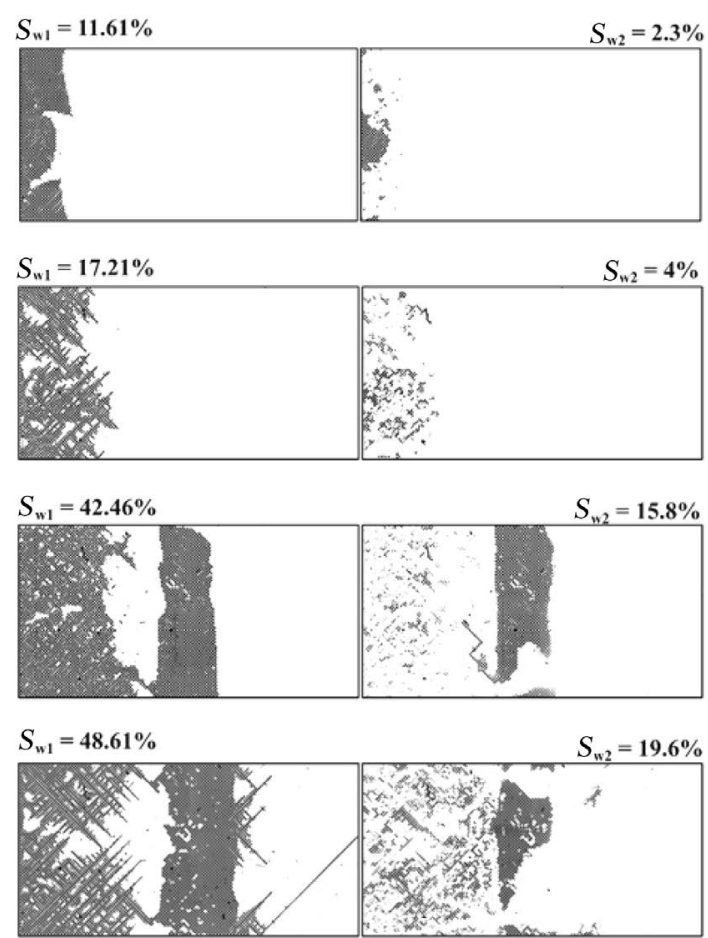

Figure 5. Non-ionic surfactant as invaded fluid, (represented by black color), showcasing the stitched microchip images after invasion (left column) and after flowback (right column) for different invasion efficiencies.
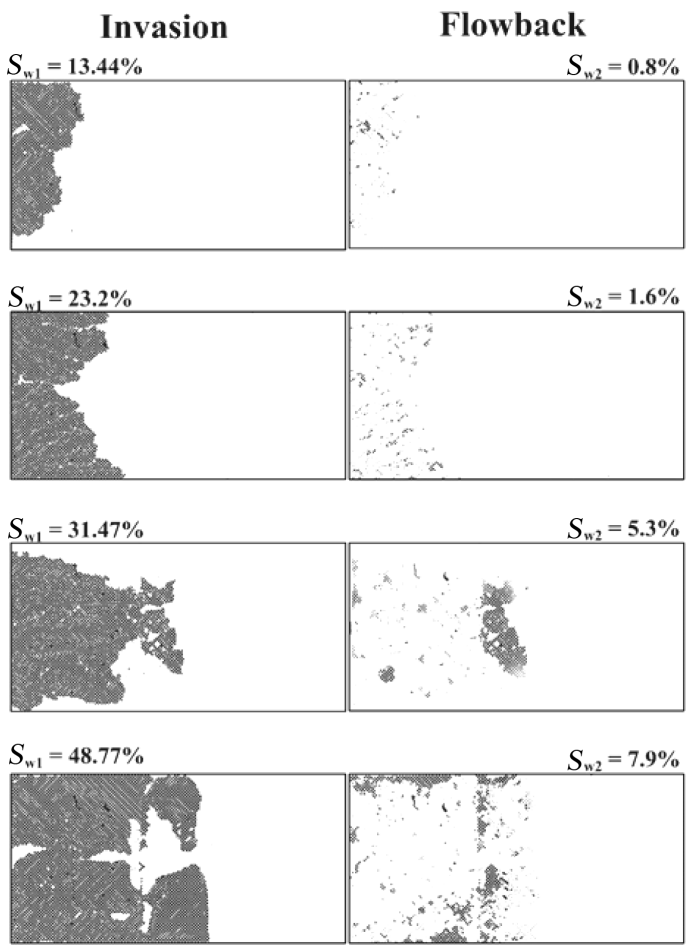

Figure 6. Anionic surfactant as invaded fluid (represented by black color), showcasing the stitched microchip images after invasion (left column) and after flowback (right column) for different invasion efficiencies. 
The relationship between the invasion amounts of the fracture fluid with the respective residual saturations of the invaded fracture fluid after the flowback phase i.e. the later production phase, $S_{\mathrm{w} 2}$, is shown in Figure 7.

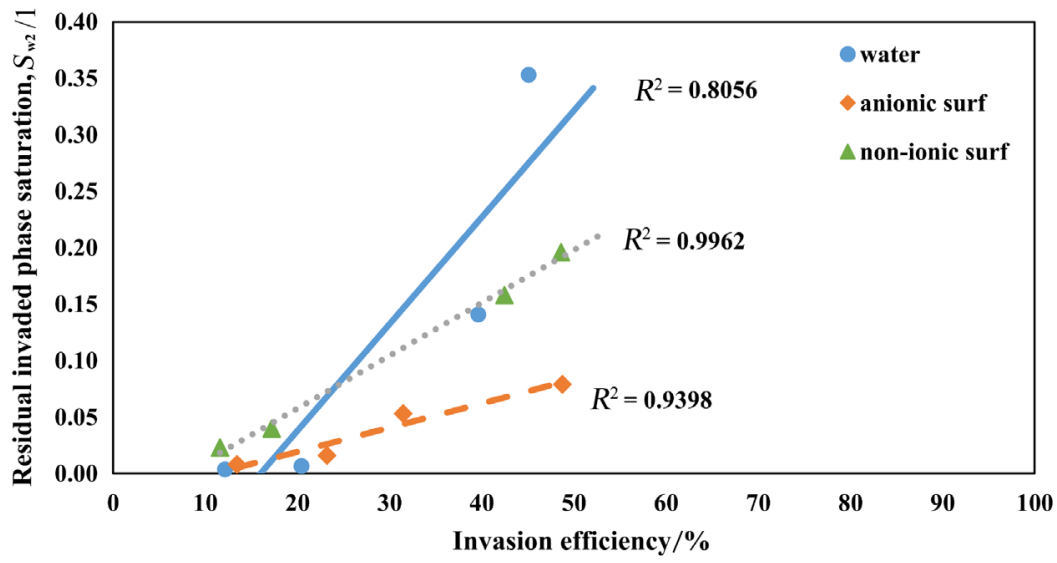

Figure 7. Relation between invasion efficiencies and invaded phase saturation after flowback.

For the purpose of simple qualitative comparison, linear trend lines are plotted over the data points, due to the unknown nature of the degree of relationship of the mentioned parameters beforehand. According to the figure, irrespective of the type of fracture fluid, it can be observed that as the invasion efficiency increases, the residual saturation of invaded fluid also increases. It can be attributed to the increase in the amount of capillary trapping of the non-wetting fluid within the pores, as a larger amount of fracture fluid is invaded. Such an increase in the residual saturations of the fracture fluid, results in a reduction in the relative permeability of oil which is reflected as formation damage and hence the later oil production rates could be severely affected. This trend is clearly depicted in Figure 8 for all the three types of invaded fluid, which shows a decreasing trend for the measured final oil rate, as the invasion efficiency is increased.

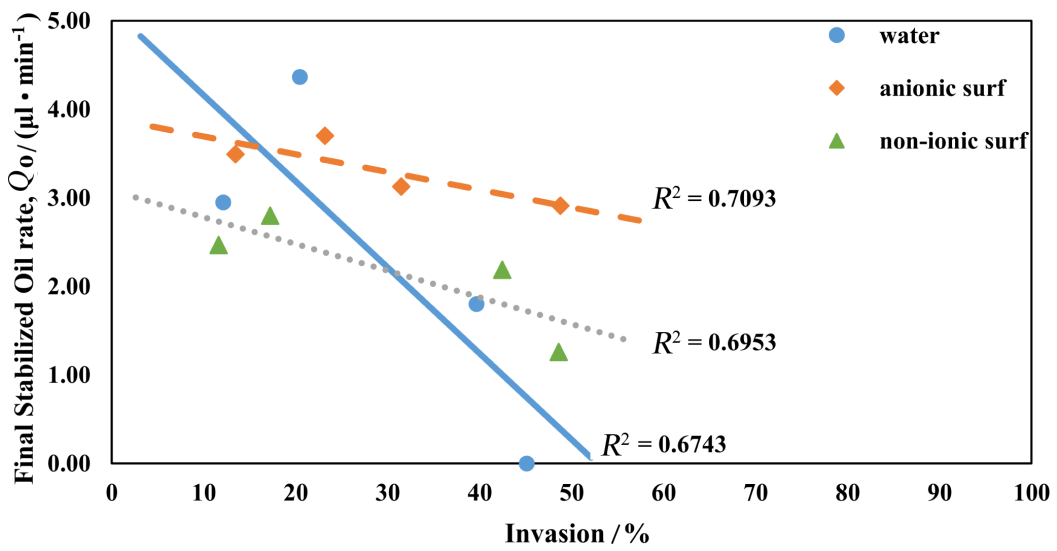

Figure 8. Relation between invasion efficiency and production rate of oil after flowback phase. 
The efficiency for the process of retrieval of the invaded fluid during the production phase is to be defined with respect to the amount of invasion, and is represented by a quantity, flowback efficiency, which is defined as follows:

$$
\text { Invasion efficiency }(\%)=S_{\mathrm{w} 1} \times 100 \%
$$

where $S_{\mathrm{w} 1}=$ Invaded fluid saturation after invasion process

$$
\text { Flowback efficiency }(\%)=\frac{S_{\mathrm{w} 1}-S_{\mathrm{w} 2}}{S_{\mathrm{w} 1}} \times 100 \%
$$

where $S_{\mathrm{w} 2}=$ Residual saturation of the invaded fluid during later production phase (i.e. after $10 \mathrm{PV}$ of production).

The relation between the invasion efficiency and the flowback efficiency for all the type of fluids is shown in Figure 9.

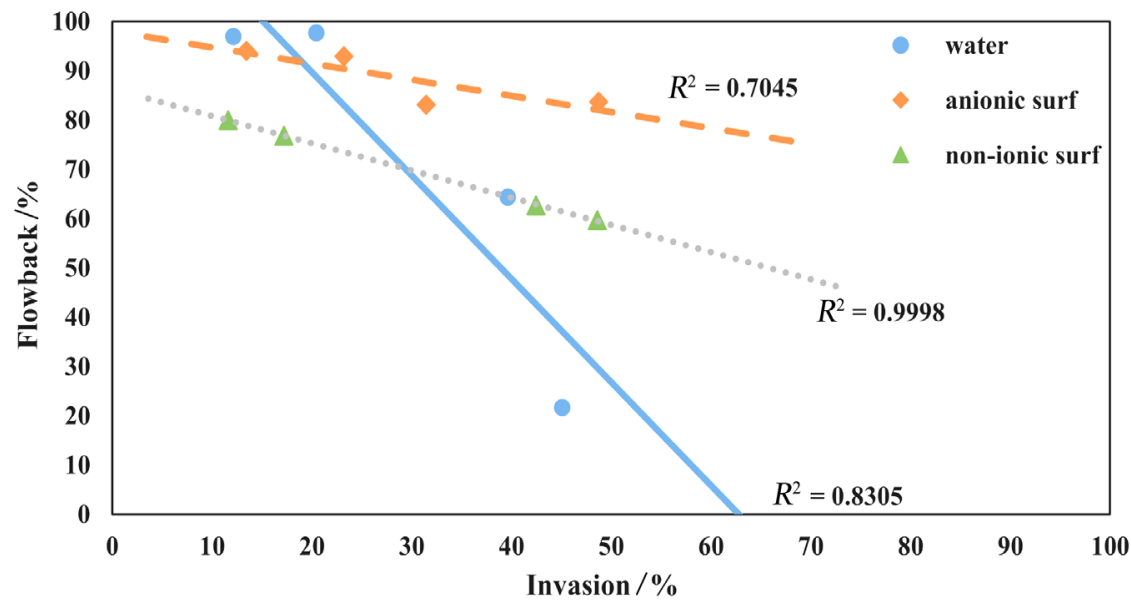

Figure 9. Relation between invasion efficiency and flowback efficiency.

Based on the obtained results, it can be observed that for an oil-wet chip, the flowback efficiency decreases as the invasion efficiency increases. Such an observation refers to the non-uniform nature of the distribution of residual saturations of the invaded phase across the chip. For the sake of convenience of the discussion, the points of the intersection of water and surfactant curves from Figure 9 are chosen as the critical points of invasion, above which all invasion efficiencies are considered high and that below are considered as low invasions. The invaded fluids near the matrix-fracture interface, experience an additional driving force during the flowback due to the existence of the capillary pressure discontinuity between the high conductive fracture and the low conductive matrix space. The saturation of the connected non-wetting phase is reduced to the lowest in the oil-wetting matrix near the fracture face due to the capillary driving force acting across the interface, which results in a high amount of flowback efficiency at low invasions of fracture fluid. Conversely, for high invasions of the fracture fluid, the influence of this additional driving force is decreased due to the distance away from the matrix-fracture interface, which causes a decrease in the flowback efficiency as depicted in Figure 9. 
Even though the trends observed in Figures 7-9 are the same for both the water and the surfactant type of fracture fluids, the relative differences in their rates of change provide an opportunity to perform a comparative analysis between these fluids. Besides, both surfactant fluids have similar gradient in the trends. It is observed that the surfactant fluids show a striking difference in comparison with the water-based fluid, and thus are clubbed together for further analysis where they are categorized as moderate-IFT reducing surfactants. At low invasions, for the flowback phase, it can be observed that the residual saturation of the invaded surfactant fluid (for both the type of surfactants experimented) is higher than that of the invaded water-based fluid resulting in a lower final oil rate of production for the former case than the latter. This observation could be attributed to the property of the reduction of IFT by the surfactant, which reduces the average capillary pressure of the invaded region, and hence the capillary pressure gradient observed across the matrix-fracture interface would be lower than that for the case of water invasion. This effect causes a lower reduction in the residual saturation of the surfactant fluid than the water-based fluid, and gives a lower flowback efficiency for the surfactant than the water case, which is manifested as a lower reduction of formation damage. Conversely, at high invasions, the residual saturation of the invaded fluid after the production phase $\left(S_{\mathrm{w} 2}\right)$ is lower for the surfactant when compared to the water invasion. It could be attributed to the better mobilization of residual saturations by capillary de-saturation effect of the surfactant, as it increases the capillary number by approximately one order of magnitude (Table 1), and hence reduces the residual saturation of invaded fluid trapped in the pore space. Conclusively, these obtained results highlight the influence of the moderate reductions in IFT by the surfactant, and thus reduce the capillary pressure modestly, which either assist in the effective removal of formation damage caused by the invasion of fracture fluid as seen in the cases of high invasions, or contrastingly, hinder the effective removal of formation damage, as seen in the cases of low invasions.

Since all the above obtained results are applicable only to the oil-wet surface, the future work is planned to encompass observations in a water-wet microfluidic chip to understand the removal of water block at the vicinity of fracture face, thus reducing the invasion-created formation damage. Even though the capillary numbers are low in the current work, they are not as low as found in the unconventional formations. Ultra-low capillary numbers need to be achieved in the future to gain insights to the effect of trapping of fracture fluid in the matrix corresponding to shale formations.

\section{Conclusions}

Based on the observations and the discussion over the obtained microfluidic experimental results, the following summarized points could be inferred for an oil-wet chip, which are analogously applicable to an oil-wetting hydraulic fractured formation: 
- The amount of invasion and the type of fracture fluid invaded into the matrix channel network, affect the flowback efficiency and hence influence the amount of reduction of formation damage incurred due to the invasion.

- The flowback efficiency and the later oil productivity are observed to decrease with an increase in the invasion efficiency of fracture fluid into the matrix. The nearness to the matrix-fracture interface in an oil-wetting chip, is a factor which is treated accountable for such an effect as the non-wetting fluids near the matrix-fracture interface are aided by the capillary pressure gradient acting across the interface for their removal from the matrix.

- A selection criterion for fracture fluids is attained based on the observed comparative results over the later oil productivities and the flowback amounts of invaded fluids between the water and moderate IFT-reducing surfactant fluids. At low invasions of fracture fluids, the reduction of formation damage, as observed through the later oil production rate, is more for water-based fracture fluid than a moderate IFT-reducing surfactant fluid. And at high invasions, the reduction in formation damage is observed to be more for moderate IFT-reducing surfactant fluid than the water-based fluid. Capillary de-saturation of the invaded fluid by IFT reduction favors surfactant as fracture fluid for high invasions and a high capillary pressure gradient across the matrix-fracture interface favors water based-fracture fluids for low invasions.

\section{Conflicts of Interest}

The authors declare no conflicts of interest regarding the publication of this paper.

\section{References}

[1] Cook, T. and Perrin, J. (2016) Hydraulic Fracturing Accounts for About Half of Current U.S. Crude Oil Production. https://www.eia.gov/todayinenergy/detail.php?id=25372

[2] Guo, B. and Schechter, D.S. (1997) A Simple and Rigorous Mathematical Model for Estimating Inflow Performance of Wells Intersecting Long Fractures. Proceedings of the SPE Asia Pacific Oil and Gas Conference and Exhibition, Kuala Lumpur, 14-16 April 1997, 645-659.

[3] Kamath, J. and Laroche, C. (2003) Laboratory-Based Evaluation of Gas Well Deliverability Loss Caused by Water Blocking. SPE Journal, 8, 71-80. https://doi.org/10.2118/83659-PA

[4] Mahadevan, J. and Sharma, M. (2005) Factors Affecting Cleanup of Water Blocks: A Laboratory Investigation. SPE Journal, 10, 238-246. https://doi.org/10.2118/84216-PA

[5] Liang, T., Longoria, R.A., Lu, J., Nguyen, Q.P. and Dicarlo, D.A. (2015) Enhancing Hydrocarbon Permeability after Hydraulic Fracturing: Laboratory Evaluations of Shut-Ins and Surfactant Additives. Proceedings of the SPE Annual Technical Conference and Exhibition, Houston, 28-30 September 2015, SPE-175101.

[6] Liang, T., Achour, S.H., Longoria, R.A., Dicarlo, D.A. and Nguyen, Q.P. (2016) 
Identifying and Evaluating Surfactant Additives to Reduce Water Blocks after Hydraulic Fracturing for Low-Permeability Reservoirs. Proceedings of the SPE Improved Oil Recovery Conference, Tulsa, 11-13 April 2016, SPE 179601.

[7] Bertoncello, A., Wallace, J., Blyton, C., Honarpour, M. and Kabir, C.S. (2014) Imbibition and Water Blockage in Unconventional Reservoirs: Well Management Implications during Flowback and Early Production. SPE Reservoir Evaluation \& Engineering, 17, 497-506. https://doi.org/10.2118/167698-PA

[8] Gupta, N., Rai, C.S. and Sondergeld, C.H. (2013) Petrophysical Characterization of the Woodford shale. Petrophysics, 54, 368-382.

[9] Liang, T., Zhou, F., Lu, J., DiCarlo, D. and Nguyen, Q. (2017) Evaluation of Wettability Alteration and IFT Reduction on Mitigating Water Blocking for LowPermeability Oil-Wet Rocks after Hydraulic Fracturing. Fuel, 209, 650-660. https://doi.org/10.1016/j.fuel.2017.08.029

[10] Kim, J., Gomaa, A.M., Nelson, S.G. and Hudson, H.G. (2016) Engineering Hydraulic Fracturing Chemical Treatment to Minimize Water Blocks: A Simulated Reservoir-On-Chip Approach. Proceedings of the SPE International Conference \& Exhibition on Formation Damage Control, Lafayette, 24-26 February 2016, SPE 178959.

[11] Xu, W., Ok, J.T., Xiao, F., Neeves, K.B. and Yin, X. (2014) Effect of Pore Geometry and Interfacial Tension on Water-Oil Displacement Efficiency in Oil Wet Microfluidic Porous Media Analogs. Physics of Fluids, 26, 093102 1-16.

[12] Longoria, R.A., Liang, T., Nguyen, Q.P. and Dicarlo, D.A. (2015) When Less Flowback Is More: A Mechanism of Permeability Damage and Its Implications on the Application of EOR Techniques. Proceedings of the Unconventional Resources Technology Conference, San Antonio, 20-22 July 2015, SPE-178583.

[13] Cottin, C., Bodiguel, H. and Colin, A. (2010) Drainage in Two Dimensional Porous Media: From Capillary Fingering to Viscous Flow. Physical Review E, 82, 046315. https://doi.org/10.1103/PhysRevE.82.046315

[14] Lenormand, R., Touboul, E. and Zarcone, C. (1988) Numerical Models and Experiments on Immiscible Displacement in Porous Media. Journal of Fluid Mechanics, 189, 165-187. https://doi.org/10.1017/S0022112088000953

[15] Razmavar, I., Alami, F.M., Rasaei, M.R. and Nadafpour, M. (2017) Microscopic Fractal-Dimension Study of Rate and Viscosity Changes on Displacement Pattern by Use of 2D Glass Micromodel. SPE Reservoir Evaluation\& Engineering, 20, 8-18. https://doi.org/10.2118/181752-PA

[16] Tsakiroglou, C.D., Avraam, D.G. and Payatakes, A.C. (2007) Transient and Steady State Relative Permeabilities from Two Phase Flow Experiments in Planar Pore Networks. Advances in Water Resources, 30, 1981-1992. https://doi.org/10.1016/j.advwatres.2007.04.002

[17] Unsal, E., Hammond, P. and Schneider, M. (2011) Effects of Surfactant on Wettability and Oil Recovery in a Pore Network Model. Proceedings of the 16th European Symposium on Improved Oil Recovery, European Association of Geoscientists and Engineers, Cambridge, UK, 12-14 April 2011.

[18] Zhang, C., Oostrom, M. and Wietsma, T.W. (2011) Influence of Viscous and Capillary Forces on Immiscible Fluid Displacement: Pore Scale Experimental Study in a Water Wet Micromodel Demonstrating Viscous and Capillary Fingering. Energy \& Fuels, 25, 3493-3505. https://doi.org/10.1021/ef101732k

[19] Clarke, A., Howe, A.M., Mitchell, J. and Staniland, J. (2015) Mechanism of Anomalously Increased Oil Displacement with Aqueous Viscoelastic Polymer Solutions. 
Soft Matter, 11, 3536-3541. https://doi.org/10.1039/C5SM00064E

[20] Hammond, P.S. and Unsal, E. (2012) A Dynamic Pore Network Model for Oil Displacement by Wettability Altering Surfactant Solution. Transport in Porous Media, 92, 789-817. https://doi.org/10.1007/s11242-011-9933-4

[21] He, K., Xu, L., Kenzekanov, S., Yin, X. and Neeves, K.B. (2017) Rock-on-a-Chip Approach to Study Fluid Invasion and Flowback in Liquid Rich Shale Formations. Proceedings of the SPE Oklahoma City Oil and Gas Symposium, Oklahoma City, 27-31 March 2017, SPE 185088.

[22] Howe, A.M., Clarke, A., Mitchell, J., Staniland, J. and Hawkes, L.A. (2015) Visualizing Surfactant EOR in Core Plugs and Micromodels. Proceedings of the SPE Enhanced Oil Recovery Conference, Kuala Lumpur, 11-13 August 2015, SPE 174643.

[23] Ibrahim, A.S. (2009) Investigation of the Mobilization of Residual Oil Using Micromodels. Proceedings of the SPE Annual Technical Conference and Exhibition, New Orleans, 4-7 October 2009, SPE 129515.

[24] Nilsson, M.A., Kulkarni, R., Gerberich, L., Hammond, R., Singh, R., Baumhoff, E. and Rothstein, J.P. (2013) Effect of Fluid Rheology on Enhanced Oil Recovery in a Microfluidic Sandstone Device. Journal of Non Newtonian Fluid Mechanics, 202, 112-119. https://doi.org/10.1016/j.jnnfm.2013.09.011

[25] Rock, A., Hincapie, R.E., Wegner, J. and Ganzer, L. (2017) Advanced Flow Behavior Characterization of Enhanced Oil Recovery Polymers Using Glass-Silicon-Glass Micromodels that Resemble Porous Media. Proceedings of the SPE Europec 79th EAGE Conference and Exhibition, Paris, 12-15 June 2017, SPE-185814.

[26] Wegner, J. and Ganzer, L. (2017) Rock-on-a Chip Devices for High P, T Conditions and Wettability Control for the Screening of EOR Chemicals. Proceedings of the SPE Europec Featured at 79th EAGE Conference and Exhibition, Paris, 12-15 June 2017, SPE-185820.

[27] Xu, K., Liang, T., Zhu, P., Qi, P., Lu, J., Huh, C. and Balhoff, M. (2017) A 2.5-D Glass Micromodel for Investigation of Multi-Phase Flow in Porous Media. Lab on a Chip, 17, 640-646. https://doi.org/10.1039/C6LC01476C 


\section{Nomenclature}

$\begin{array}{ll}\mathrm{A} & \text { Cross sectional area of the chip, } \mathrm{m}^{2} \\ \mathrm{~N}_{\mathrm{ca}} & \text { Capillary number, dimensionless } \\ \mathrm{Q}_{0} & \text { Final oil production rate after } 10 \text { pore volumes of production, } \mu \mathrm{l} / \mathrm{min} \\ \mathrm{S} & \text { Saturation, dimensionless } \\ \mathrm{wt} \% & \text { Weight percentage of chemical in the solution, dimensionless } \\ \mu & \text { Viscosity, } \mathrm{cp} \\ \sigma & \text { Interfacial tension, } \mathrm{mN} / \mathrm{m} \\ \phi & \text { Porosity, dimensionless } \\ \text { Subscripts } \\ \mathrm{w}_{1} \quad \text { Residual water after invasion } \\ \mathrm{w}_{2} \quad \text { Residual water after flowback phase } \\ \mathrm{O}\end{array}$

